Article

\title{
Preparation and Characterization of Nanocomposite Films Containing Nano-Aluminum Nitride and Cellulose Nanofibrils
}

\author{
Shuangxi Nie ${ }^{1,2, * \mathbb{D}}$, Yuehua Zhang ${ }^{2}$, Linmao Wang ${ }^{2}$, Qin $\mathrm{Wu}^{1}$ and Shuangfei Wang ${ }^{2, *}$ \\ 1 State Key Laboratory of Biobased Material and Green Papermaking, Qilu University of Technology, \\ Shandong Academy of Sciences, Jinan 250353, China \\ 2 School of Light Industry and Food Engineering, Guangxi University, Nanning 530004, China \\ * Correspondence: nieshuangxi@gxu.edu.cn (S.N.); wangsf@gxu.edu.cn (S.W.)
}

Received: 29 June 2019; Accepted: 27 July 2019; Published: 3 August 2019

\begin{abstract}
Nanocomposites consisting of cellulose nanofibrils (CNFs) and nano-aluminum nitride $(\mathrm{AlN})$ were prepared using a simple vacuum-assisted filtration process. Bleached sugarcane bagasse pulp was treated with potassium hydroxide and sodium chlorite, and was subsequently ultra-finely ground and homogenized to obtain CNFs. Film nanocomposites were prepared by mixing CNFs with various AlN amounts (0-20 wt.\%). X-ray diffraction revealed that the crystal form of CNF-AlN nanocomposites was different to those of pure CNFs and AlN. The mechanical performance and thermal stability of the CNF-AIN nanocomposites were evaluated through mechanical tests and thermogravimetric analysis, respectively. The results showed that the CNF-AIN nanocomposites exhibited excellent mechanical and thermal stability, and represented a green renewable substrate material. This type of nanocomposite could present great potential for replacing traditional polymer substrates, and could provide creative opportunities for designing and fabricating high-performance portable electronics in the near future.
\end{abstract}

Keywords: bagasse pulp; cellulose nanofibrils; cellulose nanocomposites; nano-aluminum nitride

\section{Introduction}

Nowadays, electronic devices are developing rapidly, since manufacturers are aiming at achieving miniaturization, high power, etc. [1,2]. The partial overheating of electronic devices raises inevitable concerns of thermal failure, performance degradation, and shortened life span. Controlling the heat dissipated by electronic devices has become an increasingly urgent problem [3]. Developing materials with high thermal conductivity, low thermal expansion coefficient, low dielectric constant, high resistivity, and low cost has become an urgent challenge when manufacturing electronic devices $[4,5]$. Polymer materials have attracted increasing attention due to their excellent processability and low costs [6,7]. Cellulose is the most abundant and renewable natural polymer on Earth and is also inexpensive and biodegradable [8-10]. Thus, the development and utilization of cellulose represents a research hot spot [11-13]. Cellulose nanofibrils (CNFs) have large specific surface areas, low density $\left(1.6 \mathrm{~g} / \mathrm{cm}^{3}\right)$, and a large number of $-\mathrm{OH}$ side groups, which help them graft onto chemicals to obtain different surface properties [14-17]. Since they are able to form hydrogen bonds, CNF macromolecules are more tightly packed than cellulose macromolecules, and sheet materials prepared using CNFs exhibit higher physical strength $[18,19]$.

At present, the thermal conductive materials used to manufacture electronic products mainly consist of isotropic polymer composites and thermal conductive fillers because of their good processing performance, good flexibility, and low cost [20]. Compared to isotropic heat conducting materials, 
CNF films exhibiting anisotropic thermal conductivity and ideal mechanical properties can dissipate heat in the direction of the plane. This observation is of great significance for developing the next generation of portable and foldable electronic devices [21]. However, CNFs have limitations as a thermal conductive material. One way to enhance the thermal conductivity of CNFs is to introduce a high thermal conductivity filler, such as alumina, aluminum nitride (AIN), boron nitride, and silicon nitride, into the CNF matrix [22-24]. AlN particles have been widely studied because of their high thermal conductivity $(320 \mathrm{~W} / \mathrm{mK}$ ), high resistivity (greater than $1014 \Omega$ ), low dielectric constant and dielectric loss, and lack of toxicity. Moreover, AlN is an ideal material for applications requiring materials exhibiting both good thermal conductivity and electrical insulating properties [25]. Thus, AlN thin films are often used for mechanical, electrical, and optical applications [26]. The preparation of CNF-AlN composites can provide new ideas for solving the key poor thermal conductivity concern of cellulosic materials [27]. However, the polarity and hydrophilicity of CNFs are very strong, while AlN is non-polar and hydrophobic; therefore, they present significantly different polarities. Furthermore, the water dispersion of such composites is not good.

In this study, we prepared a CNF-AlN nanocomposite using a simple vacuum-assisted filtration process. Bleached sugarcane bagasse pulp was treated with potassium hydroxide and sodium chlorite, and was subsequently ultra-finely ground and homogenized to obtain CNFs. Film nanocomposites were prepared by mixing CNFs and AlN after ultrasonication. The thermal stability of the CNF-AlN nanocomposites was evaluated. This type of nanocomposites presents great potential for replacing the traditional polymer substrates, and provides creative opportunities for designing and fabricating high-performance portable electronics in the near future.

\section{Materials and Methods}

\subsection{Raw Materials and Chemicals}

Bleached bagasse pulp was purchased from Guangxi Guitang Co., Ltd. (Guangxi, China). The raw material was obtained through caustic soda pulping, using an alkali content of $17.5 \%$, liquid ratio of 1:3.5, heating time of $45 \mathrm{~min}$, maximum cooking temperature of $165^{\circ} \mathrm{C}$, and holding time of $110 \mathrm{~min}$. The bleaching of bagasse fibers was carried out using the $\mathrm{CEPP}_{1} \mathrm{P}_{2}$ process. The whiteness of the bleached bagasse pulp was approximately $85 \%$ ISO. Potassium hydroxide and sodium chlorite were purchased from Aladdin (Shanghai, China), aluminum nitride (nanopowder, $<100 \mathrm{~nm}$ particle size) was purchased from Sigma-Aldrich (Saint Louis, MO, USA), and glacial acetic acid was purchased from Tianjin Zhiyuan Chemical Reagent Co., Ltd. (Tianjin, China). All reagents were of medicinal or analytical quality.

\subsection{Experimental Methods}

\subsubsection{Preparation of CNFs}

The concentration of purified pulp was adjusted to $3 \mathrm{wt} . \%$, and then ultrafine grinding was carried out using an ultrafine grinder (MKZA 10-15JIV, Kawaguchi, Japan). The speed of the millstone was set to $1500 \mathrm{rpm}$, the gap of the mill disc was adjusted to $-100 \mu \mathrm{m}$, and the pulp underwent six grinding 6 cycles. The samples were homogenized using a high-pressure homogenizer (M-110EH-30, Westwood, CA, USA). When the pressure reached 350 bar, the samples passed through the homogenizer five times, while at 1500 bar, the samples passed through the homogenizer 15 times. After the high-pressure homogenization process, uniform CNFs were obtained.

\subsubsection{Preparation of CNF-AIN Composite Films}

The CNF suspension was diluted to a concentration of $0.1 \mathrm{wt} . \%$, and then AlN was added to obtain a CNF-AlN mixed suspension. The amounts of added AlN were 0, 2, 5, 10 and $20 \mathrm{wt} . \%$ of the $\mathrm{CNF}$ amount. The mixed suspension was ultrasonically treated for $4 \mathrm{~h}$ with a power of $800 \mathrm{~W}$. Then, 
a magnetic stirrer was used to stir for $6 \mathrm{~h}$ at a $400 \mathrm{rpm}$ speed. The mixed suspension was vacuum filtered through a polytetrafluoroethylene (PTFE) membrane (pore size of $0.22 \mu \mathrm{m}$, diameter of $9 \mathrm{~cm}$ ). The PTFE filter and wet CNF samples were both transferred to a sheet former (HAAGE Sheet Former BB, Mülheim an der Ruhr, Germany), where they were dried for 50 min at $50{ }^{\circ} \mathrm{C}$.

\subsection{Analysis Methods}

\subsubsection{Transmission Electron Microscopy (TEM) Analysis}

We diluted the CNFs and AlN to a concentration of $0.008 \mathrm{wt} . \%$ and then the sample was dripped onto the supporting film and dried. Furthermore, 1\% uranium acetate was used to stain the film for $20 \mathrm{~min}$ in the dark and then the excess dye was absorbed using the filter paper and then dried naturally. Lastly, TEM (HT7700, Tokyo, Japan) was used to analyze the samples.

\subsubsection{Scanning Electron Microscopy (SEM) Analysis}

A small piece of CNF-AlN composite film was fixed onto the loading stage of a SEM device using conductive adhesive. The surface was sprayed using a gold spraying current of $10 \mathrm{~mA}$. The cross-section detection of membrane is to fix the membrane using liquid nitrogen and then conductive adhesive was used to fix it onto the loading stage. The cross section was sprayed with gold using an injection current of $10 \mathrm{~mA}$. The surface and cross-sectional morphologies of the samples were analyzed using SEM (Phenom F16502, Eindhoven, Netherlands).

\subsubsection{Ultraviolet-Visible (UV-Vis) Spectrum Analysis}

The transmittance of the CNF-AlN composite films was analyzed using an ultraviolet-visible (UV-Vis) spectrophotometer (Lambda 950, Waltham, MA, USA). First, air was used as reference, and the composite film was cut into $0.9 \times 4 \mathrm{~cm}$ strips, which were placed in a petri dish. The measurement range was 190-1100 $\mathrm{nm}$ and the measuring speed was $50 \mathrm{~nm} / \mathrm{s}$.

\subsubsection{Fourier-Transform Infrared Spectroscopy (FTIR) Analysis}

The CNF-AIN composites were analyzed using FTIR (TENSOR II, Ettlingen, Germany). First, the CNF-AlN mixture was freeze-dried to convert it into powder and potassium bromide (KBr) was added into the oven, where the powder was dried for $4 \mathrm{~h}$. During the test, we first used the KBr lapping press as background, then mixed the sample with $\mathrm{KBr}$ at a 1:100 ratio. The pressing pressure and time were 50-60 MPa and $2 \mathrm{~min}$, respectively. The resolution of the instrument was $0.4 \mathrm{~cm}^{-1}$ and the test was performed in the $400-4000 \mathrm{~cm}^{-1}$ range.

\subsubsection{X-Ray Diffraction (XRD) Analysis}

The CNF-AlN composite thin films were cut into $1.5 \times 1.5 \mathrm{~cm}$ pieces on the carrier platform and their degree of crystallinity was analyzed by using high resolution XRD (MINFLEX600, Tokyo, Japan). The test parameters were as follows: $\mathrm{Cu} \mathrm{K} \alpha$ radiation, the wavelength of $0.15418 \mathrm{~nm}$, scanning range of $10^{\circ}-70^{\circ}$, the scanning rate of $5^{\circ} / \mathrm{min}$, tube voltage of $40 \mathrm{kV}$, and tube current of $30 \mathrm{~mA}$.

\subsubsection{Mechanical Properties Analysis}

The CNF-AlN composite film was cut into $5 \times 50 \mathrm{~mm}$ rectangles. The mechanical properties of the samples were tested using a vertical universal tension machine (AMETEK LS1, Berwyn, PA, USA). The test conditions were as follows: The distance of the sample was $2 \mathrm{~cm}$, the tensile speed was $1 \mathrm{~mm} / \mathrm{min}$, and five samples were tested in parallel. 


\subsubsection{Thermogravimetric (TG) Analysis}

Thermogravimetric analysis of the freeze-dried samples was carried out using a synchronous thermal analyzer (STA 449F5, Selbu, Germany). The experimental conditions were as follows: samples weighing approximately $10 \mathrm{mg}$ were collected as the temperature increased from 25 to $800^{\circ} \mathrm{C}$ under nitrogen protection, the scanning rate was $10^{\circ} \mathrm{C} / \mathrm{min}$, and the nitrogen flow rate was $20 \mathrm{~mL} / \mathrm{min}$.

\section{Results and Discussion}

\subsection{Characterization of CNFs and AlN Suspension}

Due to the complex multilayer structure of plant fibers and the high number of hydrogen bonds, the mechanically prepared CNFs presented a wide diameter distribution [28]. For fiber composites, the aspect ratio of the fiber affects its ability to combine with other materials, which largely determines the mechanical properties of the composite [29,30]. Figure 1 illustrates the TEM images of CNFs and AlN. The convergence of CNFs and single root CNFs can be observed from Figure 1a. The width of the CNFs prepared using a mechanical method was smaller than $100 \mathrm{~nm}$, the length and width were relatively large, and the fibers were intertwined with each other into a tree-like structure. Such structures could explain the relatively superior mechanical and thermal properties of CNF composites. The width of AlN in Figure $1 \mathrm{~b}$ was also within $100 \mathrm{~nm}$, which allowed AlN to be better dispersed in CNFs, thus being beneficial to the preparation of CNF-AlN composites with superior performance. The mixing uniformity of CNFs and AlN greatly influenced the optical and mechanical properties of the prepared composite films. The CNF-AlN mixed suspension was sonicated, and the suspension was analyzed. Subsequently, the suspension was allowed to stand for 15 days while it dispersed, as shown in Figure 2. It can be seen that pure CNFs were dispersed in the aqueous solution to form a transparent CNF suspension.
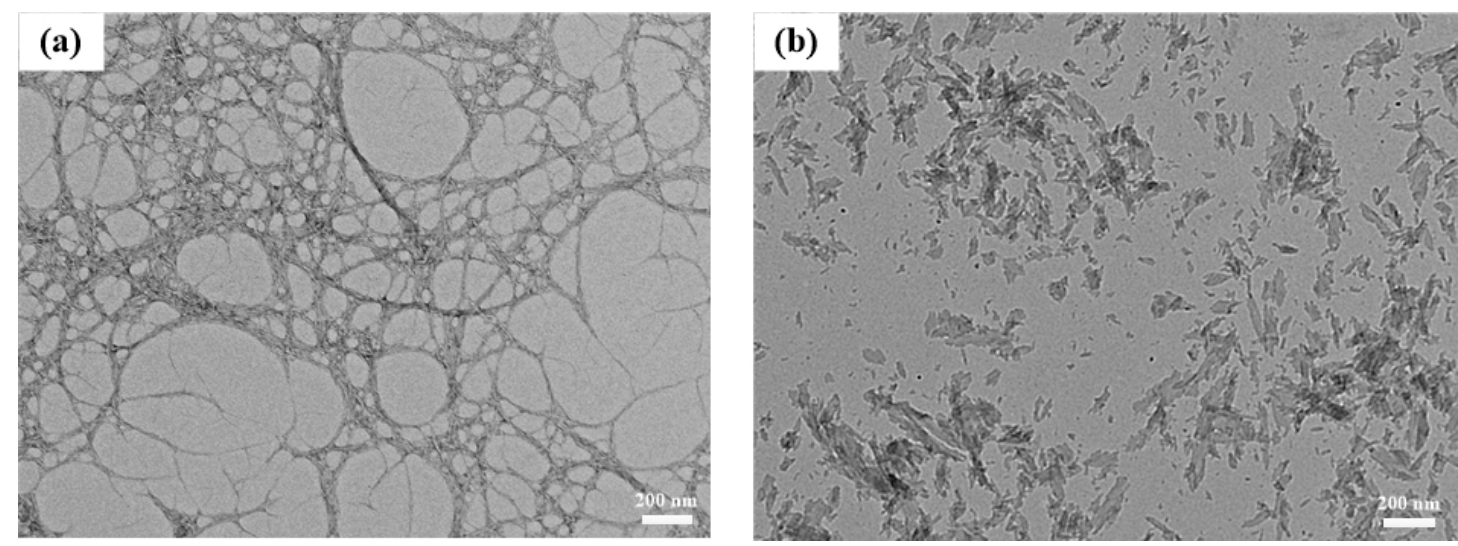

Figure 1. TEM images of (a) cellulose nanofibrils (CNFs) and (b) nano-aluminum nitride (AlN).

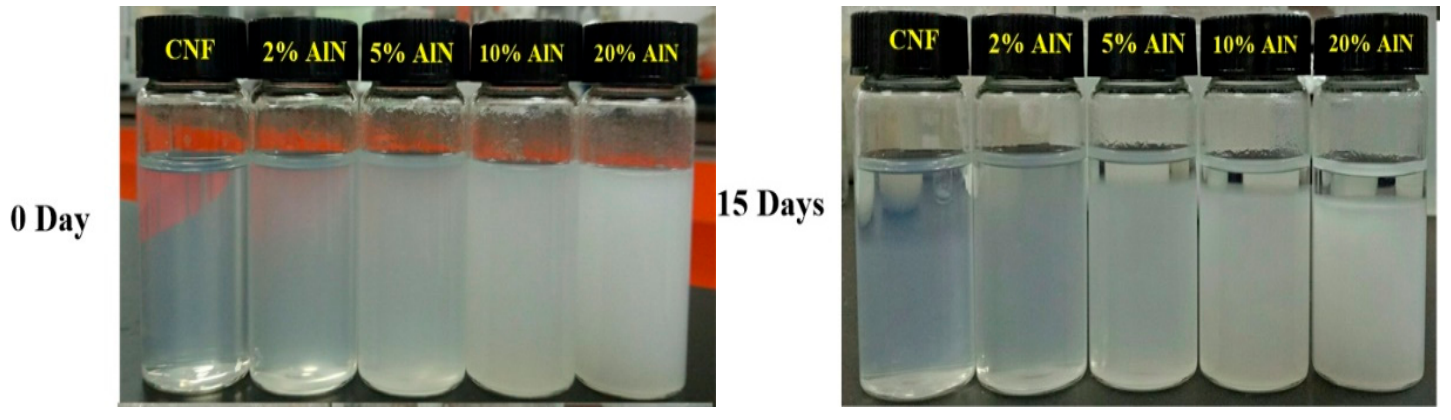

Figure 2. CNF-AlN suspensions with different contents. 
To examine the optical properties of the CNF-AlN composite films, the prepared CNF-AlN composite films were photographed in a well-lit laboratory and the changes in their appearance were analyzed. The results are shown in Figure 3. As can be seen from Figure 3a, when the composite film was placed on the red Guangxi University logo as background, the pure CNF film allowed the logo to be clearly visible in the background. As the amount of AlN added to CNF increased, the transparency of the composite film gradually decreased. When the AlN content was $20 \%$, the logo was no longer visible. To reduce the influence of the human factor on the experimental results, changes in the light transmittance of CNF-AlN composites containing different amounts of AlN were measured using an UV-vis spectrophotometer. The results are shown in Figure $3 b$. The transmittances of CNF-AlN composites containing different amounts of AlN were quite different. The transmittance of the pure CNF films could reach approximately $80 \%$. The transmittance of the CNF-AlN composite containing $5 \%$ AlN was reduced to $35 \%$. When the amount of added AlN exceeded $10 \%$, the light transmittance of the composite material was already reduced to $5 \%$ or less. Paper with custom optical properties could be used for various purposes, and pure CNF films exhibiting good light transmission could be used for electronic displays, and a composite paper containing $20 \mathrm{wt}$ \% AlN could be used as opaque substrate in flexible solar panels.
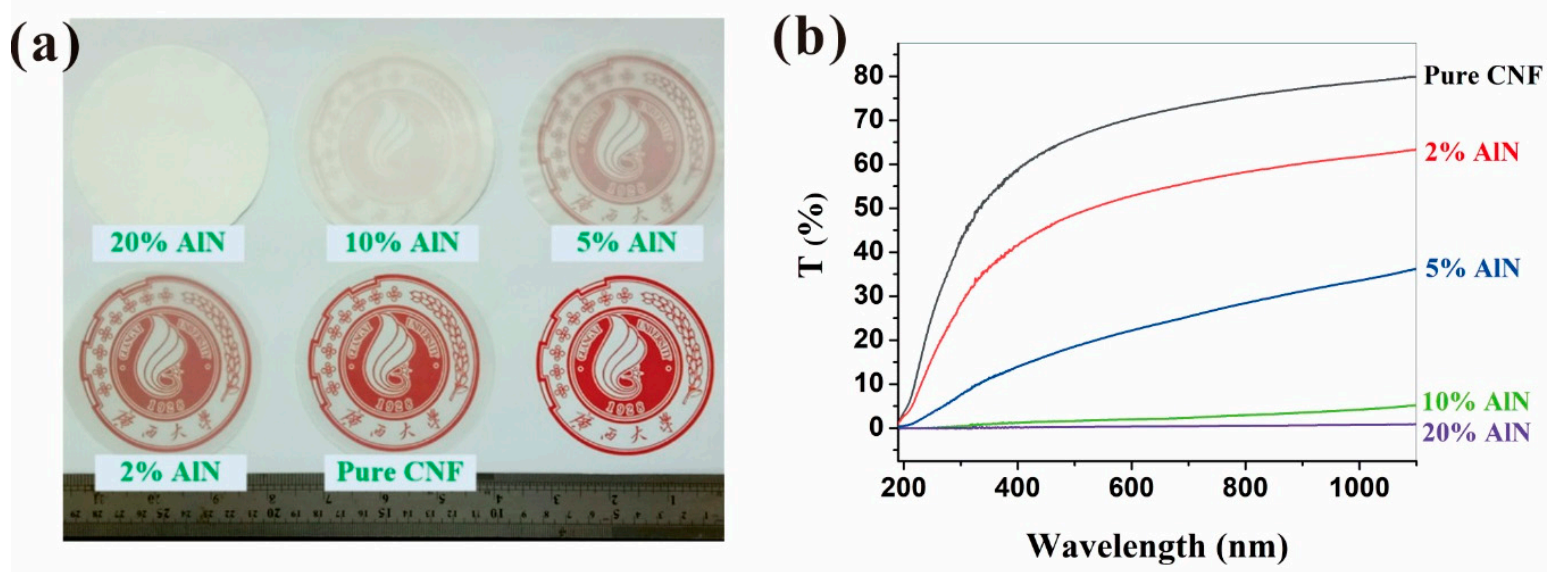

Figure 3. Optical properties of CNF-AIN composites: (a) Optical images and (b) transmittance.

\subsection{Microscopic Analysis of CNF-AlN Composites}

The surface and cross section of the CNF-AlN composite were observed by SEM, as shown in Figures 4 and 5. After the image in Figure 4 was magnified 10,000 times, we were able to observe that that AlN was uniformly dispersed in the CNF matrix. As the amount of added AlN increased, the AlN distribution is highly uniform and that AlN is interlaced with CNFs in a network structure. This was due to the interweaving between the CNF macromolecules to form a network-like porous sheet material. As a result, the surface of the film in Figure 4a presented cracks. As AlN was added to CNFs, the interfiber spaces were filled (Figure $4 \mathrm{~b}, \mathrm{c}$ ). However, as the amount of added AlN increased, too much AlN would become exposed at the surface (Figure $4 \mathrm{~d}, \mathrm{e}$ ).

Figure 5 shows a cross-sectional topography of the composite film. Since the hydrogen bonds between the fibers caused the fibers to form a complex multilayer structure, the CNF film formed a distinct layered structure (Figure 5a). After AlN was added, the AlN particles became dispersed in the cellulose matrix, and when the amount of added AlN was 5\% or smaller, the layered structure was still conspicuous (Figure 5b,c). However, as the amount of added AlN increased, the layered structure of the composite material gradually became blurred (Figure 5d,e). When the amount of added AlN was $10 \%$ or more, a large amount of AlN in the CNFs became agglomerated and destroyed the layered structure of CNFs. Destroying the layered structure of the composite would lead to a reduction of the mechanical properties of the composite, while further hindering the contact between AlN particles, thus preventing them from forming a network structure. 

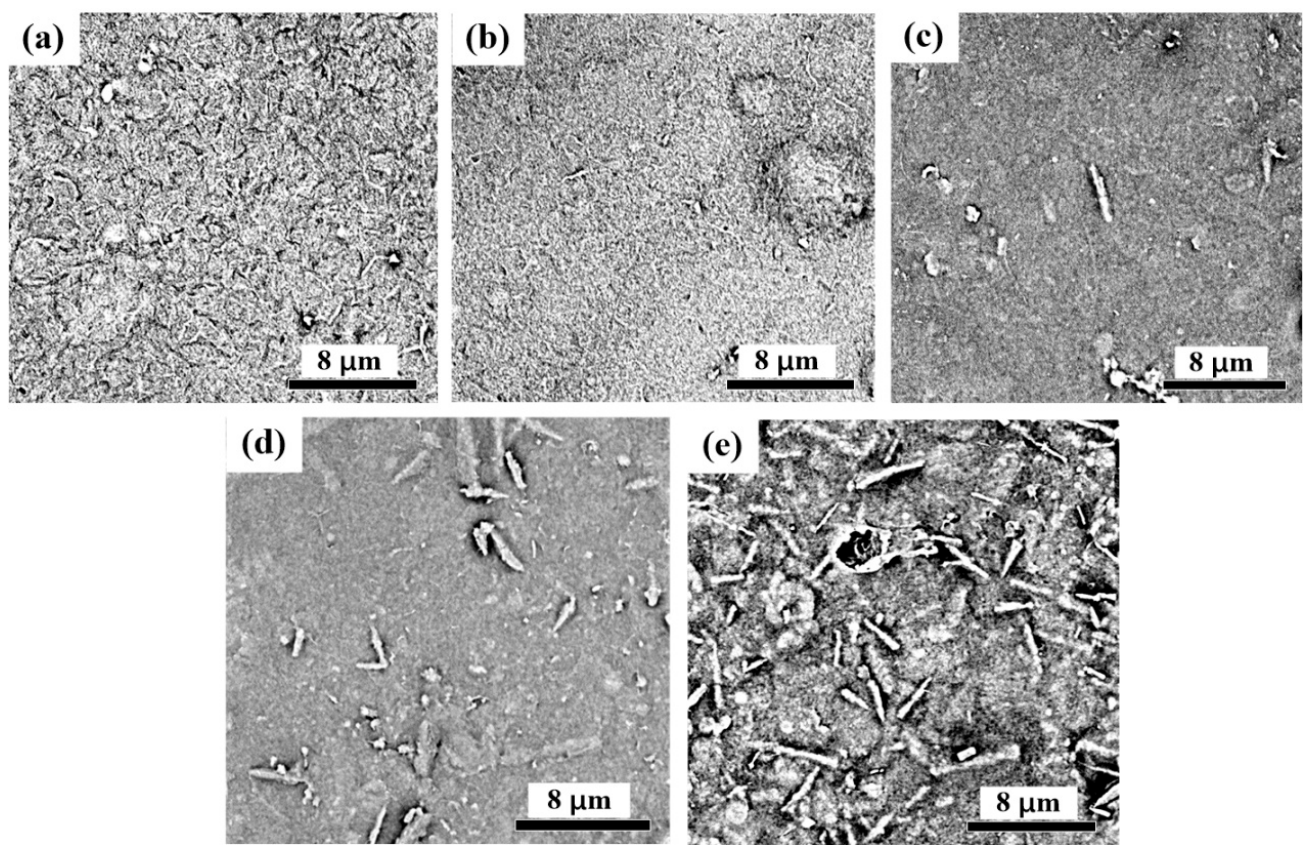

Figure 4. SEM images of the surfaces of CNF-AlN composites: (a) Pure CNFs; CNFs containing (b) $2 \%$ $\mathrm{AlN}$, (c) $5 \% \mathrm{AlN}$, (d) $10 \% \mathrm{AlN}$, and (e) $20 \% \mathrm{AlN}$.
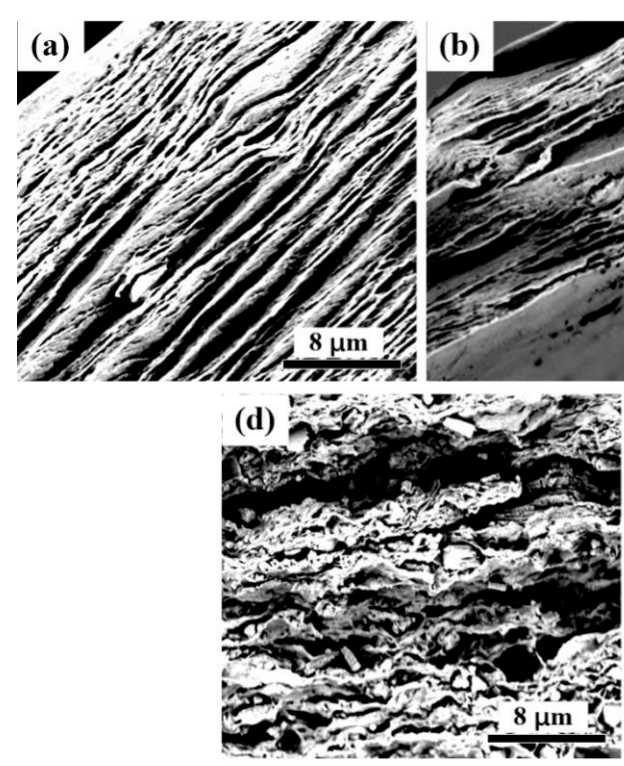
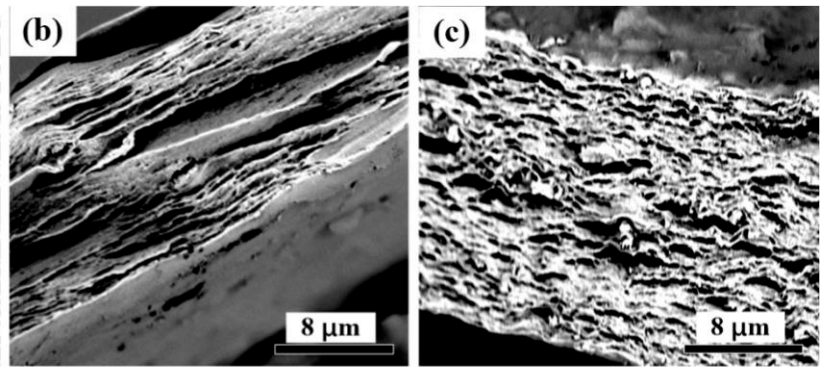

(e)

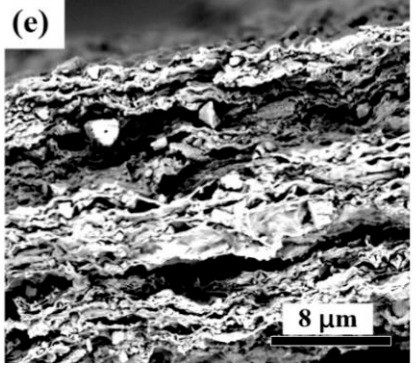

Figure 5. SEM images of the cross section of CNF-AlN composites. (a) Pure CNFs and CNFs containing (b) $2 \% \mathrm{AlN}$, (c) $5 \% \mathrm{AlN}$, (d) $10 \% \mathrm{AlN}$, and (e) $20 \% \mathrm{AlN}$.

\subsection{FTIR Analysis of CNF-AlN Composites}

The functional groups of CNF-AlN composites were analyzed using FTIR to study the effect of the chemical structure on the properties of composites. We performed FTIR analysis on pure CNFs and CNF composites containing 10\% AlN. The obtained spectra are shown in Figure 6. It can be seen from Figure 6 that the spectrum of the CNF composite containing $10 \%$ AlN was very similar to that of pure CNFs, where the $3200-3500 \mathrm{~cm}^{-1}$ peak represented a hydrogen-bonded $-\mathrm{OH}$ stretching vibration peak, and the $2910 \mathrm{~cm}^{-1}$ peak represented the symmetric stretching vibration absorption peak of $\mathrm{C}-\mathrm{H}$ or $-\mathrm{CH}_{2}$. The $1430 \mathrm{~cm}^{-1}$ peak corresponded to the $-\mathrm{OCH}$ in-plane bending vibration, and the $1372 \mathrm{~cm}^{-1}$ and $1065 \mathrm{~cm}^{-1}$ peaks were attributed to the stretching vibrations of the $\mathrm{C}-\mathrm{O}$ asymmetric bond and the $\mathrm{C}-\mathrm{O}-\mathrm{C}$ bond, respectively $[31,32]$. Pure AlN exhibited a very strong absorption peak at $731 \mathrm{~cm}^{-1}$, 
which represented the stretching vibration absorption peak of Al-N. However, this absorption peak was not detected in the spectrum of the CNF-AlN composite. Since AlN has a melting point of roughly $2000{ }^{\circ} \mathrm{C}$ it will not easily dissociate. Moreover, the entire material preparation process used only ultrasonic and vacuum filtration treatments, the two treatment methods would not have been sufficient to break the Al-N bonds. It is most likely that the phonon (lattice vibration) is not observed because the cross section is low or maybe, due to the low transparency (as shown in Figure 3), the light cannot easily penetrate the sample.

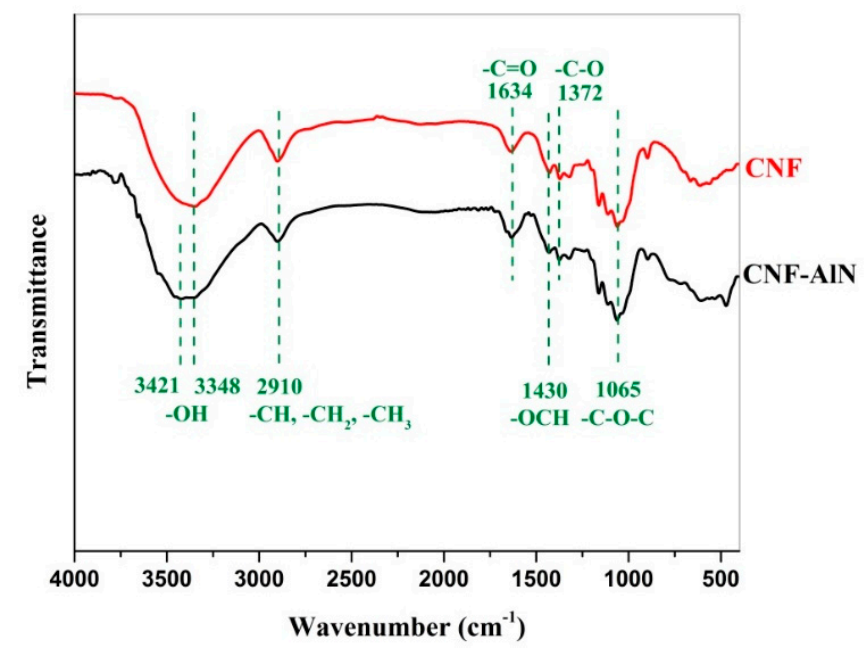

Figure 6. FTIR spectra of CNF and CNF-AIN composites.

\subsection{XRD Analysis of CNF-AlN Composites}

Analyzing XRD patterns is an effective method to determine the crystallinity of a sample. Crystallinity is an important parameter for characterizing the properties of polymers. Some physical and mechanical properties of polymers are closely related to their crystallinity. Figure 7 shows the X-ray diffraction pattern of the pure AlN, pure CNF and AIN/CNF samples. It can be seen that the XRD patters of pure CNF displayed peaks at $2 \theta=16.68^{\circ}$, and $22.1^{\circ}$, corresponding to the (110) and (200) crystallographic planes, which are in agreement with the characteristic diffraction peaks of cellulose $I \beta$ [33]. The diffraction peaks of AlN mostly concentrate in the range of $2 \theta=36^{\circ}-70^{\circ}$. As the amount of added AlN increased, the intensities of the diffraction peaks of the composites at the (110) and (200) planes gradually decreased. When the AlN content of the composite was $10 \%$, additional characteristic diffraction peaks of AlN could be observed at $2 \theta$ of $39^{\circ}$ and $63.6^{\circ}$ [26]. Moreover, as the AlN content increased, the intensity of the characteristic diffraction peak of AlN gradually increased.

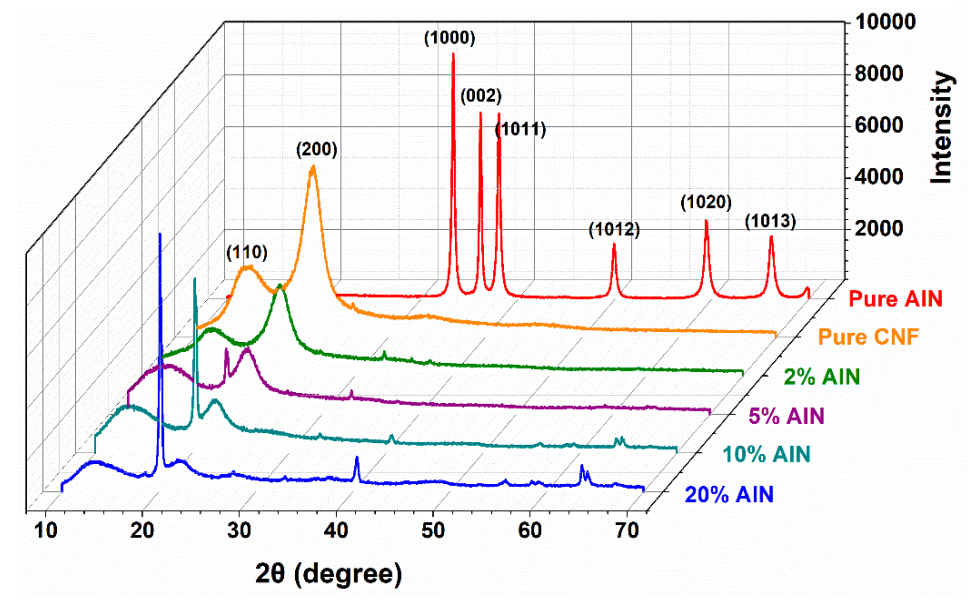

Figure 7. XRD spectra of the pure AlN, pure CNF and CNF-AlN composites. 


\subsection{Mechanical Properties of CNF-AlN Composites}

Mechanical properties are very important performance indices of CNF-AlN composites, which play decisive roles in their application ranges. Figure 8 shows the mechanical properties testing results of CNF-AlN composites. It can be seen from Figure 8 that the tensile strength and elongation at break of the CNF-AlN composite could reach $142.5 \mathrm{MPa}$ and $0.24 \%$, respectively, when the added AlN amount was $2 \%$. This occurred because when the amount of added AlN was small, CNF acted like an adhesive to tightly bind the AlN nanosheets together. Thus, the AlN nanosheets in the CNF became well aligned and the AlN particles were sufficiently connected with each other as well as with the CNF molecules. At the same time, a large number of amino $\left(-\mathrm{NH}_{2}\right)$ and hydroxyl $(-\mathrm{OH})$ groups existed at the edge of AlN, and these easily formed hydrogen bonds with the $-\mathrm{OH}$ and carboxyl $(-\mathrm{COOH})$ groups on the surface of CNF [20]. A nanocomposite exhibiting high mechanical strength would be formed by hydrogen bonding. It can be seen from the cross-sectional morphology of the CNF-AlN composite film (Figure 5) that the uniform CNF-AlN suspension formed a three-dimensional structure presenting stacked layers and compact, dense, and regular features when vacuum filtration and high vacuum conditions were used. An orderly and uniform structure was formed between CNF and AlN through strong interfacial interactions. This special structure also represented an important reason for the formation of nanocomposites exhibiting high mechanical strength. As the amount of added AlN increased, the tensile strength and elongation at break of the composites were gradually reduced, as AlN itself exhibited high brittleness and was not easily interwoven into a film. For the CNF-AlN composites, as the amount of added AlN increased, gaps occurred between the CNF fibers and a large amount of AlN was agglomerated between the CNF fibers, destroying the layered structure of the composite. The strength of the hydrogen bonds was inversely related to the AlN content, resulting in a gradual decrease in tensile strength and elongation at break of the composite.

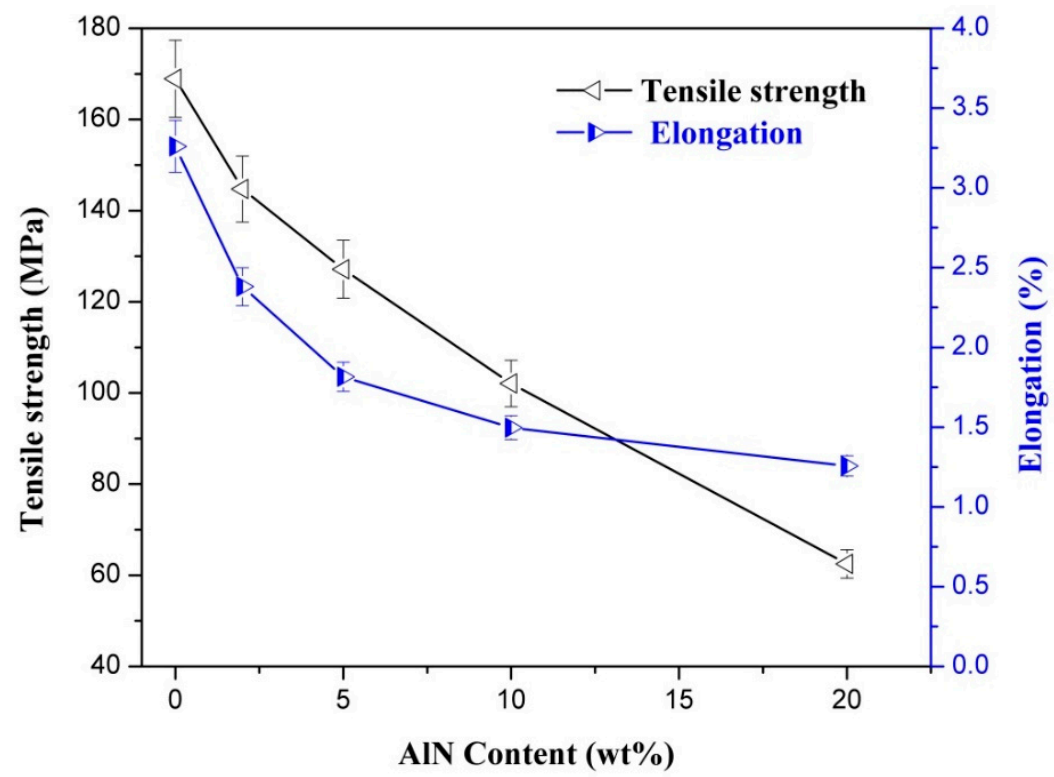

Figure 8. Mechanical properties of CNF-AlN composite reinforced with different amounts of AlN: (a) Tensile strength; (b) elongation.

\subsection{Thermal Stability of CNF-AlN Composites}

In recent years, CNF composites have been increasingly used and are expected to substitute traditional organic polymer materials. However, they also undergo thermal degradation at high temperatures. Recently, scholars have focused on studying the thermal stability of cellulose [34-37]. These studies could provide a clearer understanding of the pyrolysis mechanism of cellulose and provide references for obtaining CNF composites with superior thermal properties. The TG curves of 
the CNF-AlN composite containing different $\mathrm{AlN}$ amounts obtained at a heating rate of $10{ }^{\circ} \mathrm{C} / \mathrm{min}$ are shown in Figure 9. The TG curves of each sample could be divided into three regions based on the changes in weight percentage of the sample as the temperature increased. As can be seen from Figure 9 , the $25-220^{\circ} \mathrm{C}$ range represented Region I, defined as the initial mass loss phase, and the CNF-AlN composite materials containing different amounts of AlN presented large mass losses in this region. The mass loss in Region I was mainly due to the evaporation of water from the CNF-AIN composites, as no thermal degradation occurred at this stage [14]. The final temperature of Region I $\left(220{ }^{\circ} \mathrm{C}\right)$ was defined as the thermal degradation onset temperature of the sample. Region II of the TG curves of the samples represented the main mass loss phase. As shown in Table 1, the residual mass of the pure CNF sample at the end of Region II was 25.5\%, while the residual mass of the CNF-AIN composite at the end of Region II was above 32\%. This indicated that adding AlN to CNFs could reduce the thermal degradation of CNF composites in Region II. After Region II, the mass loss rate of the CNF-AlN composites decreased. These areas of the TG curves were defined as Region III and extended from this point to the final test temperature of $800{ }^{\circ} \mathrm{C}$. For Region III, when the temperature exceeded $500{ }^{\circ} \mathrm{C}$, cellulose would decompose to produce a variety of low molecular weight products [38]. At the final test temperature of $800{ }^{\circ} \mathrm{C}$, the final residues of pure CNFs and CNF-AlN composites containing 2\%, 5\%, $10 \%$, and $20 \%$ AlN were $15.4 \% \pm 0.4 \%, 21.4 \% \pm 0.2 \%, 20.0 \% \pm 0.6 \%, 27.0 \% \pm 0.2 \%$, and $36.6 \% \pm 0.4 \%$, respectively (Table 1). It can be seen that as the AlN content increased, the mass loss of the CNF-AlN nanocomposites decreased, while the thermal stability of the CNF-AlN nanocomposites increased. Therefore, the AlN in the composite could better dissipate heat and limit the movement of the CNF polymer chains, causing the CNF polymer chains to begin to degrade at higher temperatures [39].

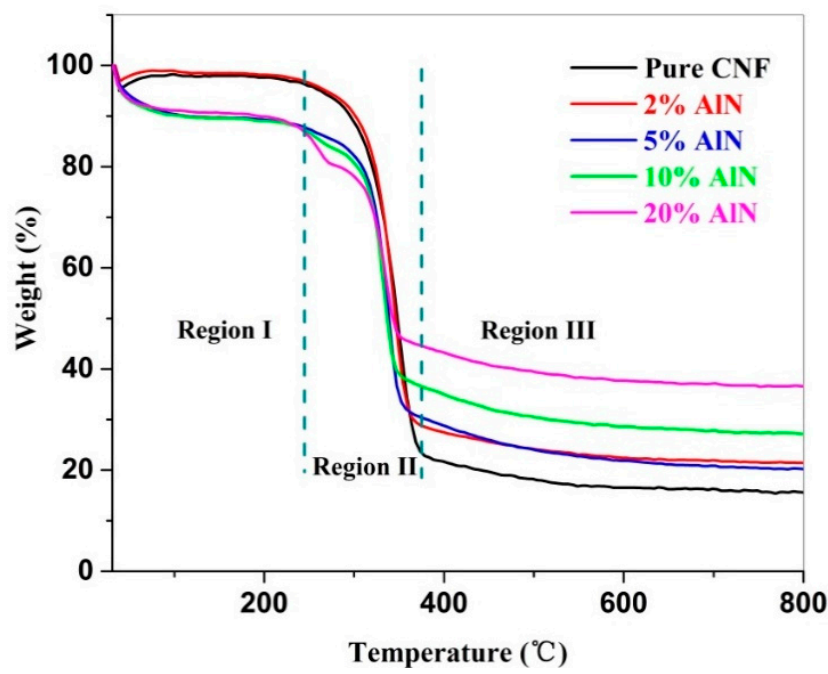

Figure 9. Thermogravimetric (TG) curves of pure CNFs and CNF-AIN composites.

Table 1. Thermal stability of CNF-AlN composites.

\begin{tabular}{cccc}
\hline \multirow{2}{*}{ Sample } & \multicolumn{3}{c}{ Mass Residue (wt.\%) } \\
\cline { 2 - 4 } & Region I & Region II & Region III \\
\hline Pure CNFs & $97.6 \pm 0.2$ & $25.5 \pm 0.5$ & $15.4 \pm 0.4$ \\
CNF-2\%AlN & $98.3 \pm 0.1$ & $32.8 \pm 0.3$ & $21.4 \pm 0.2$ \\
CNF-5\%AlN & $89.5 \pm 0.1$ & $33.5 \pm 0.8$ & $20.0 \pm 0.6$ \\
CNF-10\%AlN & $89.4 \pm 0.4$ & $39.9 \pm 0.2$ & $27.0 \pm 0.2$ \\
CNF-20\%AlN & $90.5 \pm 0.4$ & $47.5 \pm 0.7$ & $36.6 \pm 0.4$ \\
\hline
\end{tabular}

\section{Conclusions}

In this study, we prepared a CNF-AIN nanocomposite via a simple vacuum-assisted filtration process. Film nanocomposites were prepared by mixing CNFs and AlN after ultrasonication. 
We obtained CNF-AlN nanocomposites with excellent mechanical flexibility and thermal stability. This type of nanocomposites exhibits a wide-range of applications. Pure CNF films presenting good transmittance could be used for electronic displays, and the poor transmittance films could be useful for energy storage products.

Author Contributions: Data Curation and Funding Acquisition, S.N.; Writing-Original Draft Preparation, Y.Z.; Writing-Review \& Editing, S.N. and S.W.; Methodology and Resources, L.W.; Software, Q.W.; Supervision and Project Administration, S.W.

Funding: This research was funded by National Natural Science Foundation of China [31760192], The Guangxi Natural Science Foundation of China [2018GXNSFDA281050], And The State Key Laboratory of Biobased Material and Green Papermaking, Qilu University of Technology, Shandong Academy of Sciences [KF201807].

Conflicts of Interest: The authors declare no conflict of interest.

\section{References}

1. Xing, J.; Tao, P.; Wu, Z.; Xing, C.; Liao, X.; Nie, S. Nanocellulose-graphene composites- a promising nanomaterial for flexible supercapacitors. Carbohydr. Polym. 2019, 207, 447-459. [CrossRef] [PubMed]

2. Wang, L.W.; Wang, S.P.; Fu, H.; Wang, Y.H.; Yu, K.F. Synthesis of au nanoparticles functionalized $1 \mathrm{D} \alpha-\mathrm{MoO}_{3}$ nanobelts and their gas sensing properties. Nano 2018, 13, 10. [CrossRef]

3. Wu, K.; Lei, C.; Huang, R.; Yang, W.; Chai, S.; Geng, C.; Chen, F.; Fu, Q. Design and preparation of a unique segregated double network with excellent thermal conductive property. ACS Appl. Mater. Interfaces 2017, 9, 7637-7647. [CrossRef] [PubMed]

4. Chen, J.; Huang, X.; Zhu, Y.; Jiang, P. Cellulose nanofiber supported 3D interconnected bn nanosheets for epoxy nanocomposites with ultrahigh thermal management capability. Adv. Funct. Mater. 2017, 27, 1604754. [CrossRef]

5. Moore, A.L.; Shi, L. Emerging challenges and materials for thermal management of electronics. Mater. Today 2014, 17, 163-174. [CrossRef]

6. Dong, F.; Li, C.; Crittenden, J.; Zhang, T.; Lin, Q.; He, G.; Zhang, W.; Luo, J. Sulfadiazine destruction by chlorination in a pilot-scale water distribution system: Kinetics, pathway, and bacterial community structure. J. Hazard. Mater. 2019, 366, 88-97. [CrossRef] [PubMed]

7. Huang, C.; He, J.; Du, L.; Min, D.; Yong, Q. Structural characterization of the lignins from the green and yellow bamboo of bamboo culm (phyllostachys pubescens). J. Wood Chem. Technol. 2016, 36, 157-172. [CrossRef]

8. Nie, S.; Zhang, C.; Zhang, Q.; Zhang, K.; Zhang, Y.; Tao, P.; Wang, S. Enzymatic and cold alkaline pretreatments of sugarcane bagasse pulp to produce cellulose nanofibrils using a mechanical method. Ind. Crop. Prod. 2018, 124, 435-441. [CrossRef]

9. Zhang, H.; Nie, S.; Qin, C.; Wang, S. Removal of hexenuronic acid to reduce AOX formation in hot chlorine dioxide bleaching of bagasse pulp. Ind. Crop. Prod. 2019, 128, 338-345. [CrossRef]

10. Huang, C.; Dong, H.; Su, Y.; Wu, Y.; Narron, R.; Yong, Q. Synthesis of carbon quantum dot nanoparticles derived from byproducts in bio-refinery process for cell imaging and in vivo bioimaging. Nanomaterials 2019, 9, 387. [CrossRef]

11. Lin, X.; Wu, Z.; Zhang, C.; Liu, S.; Nie, S. Enzymatic pulping of lignocellulosic biomass. Ind. Crop. Prod. 2018, 120, 16-24. [CrossRef]

12. Nie, S.; Liu, X.; Wu, Z.; Zhan, L.; Yin, G.; Yao, S.; Song, H.; Wang, S. Kinetics study of oxidation of the lignin model compounds by chlorine dioxide. Chem. Eng. J. 2014, 241, 410-417. [CrossRef]

13. Yao, S.; Nie, S.; Yuan, Y.; Wang, S.; Qin, C. Efficient extraction of bagasse hemicelluloses and characterization of solid remainder. Bioresour. Technol. 2015, 185, 21-27. [CrossRef] [PubMed]

14. Zhang, K.; Zhang, Y.; Yan, D.; Zhang, C.; Nie, S. Enzyme-assisted mechanical production of cellulose nanofibrils: Thermal stability. Cellulose 2018, 25, 5049-5061. [CrossRef]

15. Yao, S.; Nie, S.; Zhu, H.; Wang, S.; Song, X.; Qin, C. Extraction of hemicellulose by hot water to reduce adsorbable organic halogen formation in chlorine dioxide bleaching of bagasse pulp. Ind. Crop. Prod. 2017, 96, 178-185. [CrossRef] 
16. Nie, S.; Zhang, K.; Lin, X.; Yan, D.; Liang, H.; Wang, S. Enzymatic pretreatment for the improvements of dispersion and film properties of cellulose nanofibrils. Carbohydr. Polym. 2018, 181, 1136-1142. [CrossRef] [PubMed]

17. Tao, P.; Wu, Z.; Xing, C.; Zhang, Q.; Wei, Z.; Nie, S. Effect of enzymatic treatment on the thermal stability of cellulose nanofibrils. Cellulose 2019, 26,1-10. [CrossRef]

18. Li, W.; Yang, Y.; Sha, J.; Zhou, J.; Qin, C.; Wang, S. The influence of mechanical refining treatments on the rheosedimentation properties of bleached softwood pulp suspensions. Cellulose 2018, 25, 3609-3618. [CrossRef]

19. Tao, P.; Zhang, Y.; Wu, Z.; Liao, X.; Nie, S. Enzymatic pretreatment for cellulose nanofibrils isolation from bagasse pulp: Transition of cellulose crystal structure. Carbohydr. Polym. 2019, 214, 1-7. [CrossRef] [PubMed]

20. Zeng, X.; Sun, J.; Yao, Y.; Sun, R.; Xu, J.B.; Wong, C.P. A combination of boron nitride nanotubes and cellulose nanofibers for the preparation of a nanocomposite with high thermal conductivity. ACS Nano 2017, 11, 5167-5178. [CrossRef]

21. Zhu, H.; Li, Y.; Fang, Z.; Xu, J.; Cao, F.; Wan, J.; Preston, C.; Yang, B.; Hu, L. Highly thermally conductive papers with percolative layered boron nitride nanosheets. ACS Nano 2014, 8, 3606-3613. [CrossRef] [PubMed]

22. Yao, Y.; Zeng, X.; Wang, F.; Sun, R.; Xu, J.-b.; Wong, C.-P. Significant enhancement of thermal conductivity in bioinspired freestanding boron nitride papers filled with graphene oxide. Chem. Mater. 2016, 28, 1049-1057. [CrossRef]

23. Fu, L.; Wang, T.; Yu, J.; Dai, W.; Sun, H.; Liu, Z.; Sun, R.; Jiang, N.; Yu, A.; Lin, C.-T. An ultrathin high-performance heat spreader fabricated with hydroxylated boron nitride nanosheets. 2D Mater. 2017, 4, 025047. [CrossRef]

24. Wu, K.; Fang, J.; Ma, J.; Huang, R.; Chai, S.; Chen, F.; Fu, Q. Achieving a collapsible, strong, and highly thermally conductive film based on oriented functionalized boron nitride nanosheets and cellulose nanofiber. ACS Appl. Mater. Interfaces 2017, 9, 30035-30045. [CrossRef] [PubMed]

25. Lv, H.; Chen, G.; Ye, H.; Yan, G.; Li, G.; Guo, J.; Sun, S. Photoluminescence of hexagonal aln nanowires with native defect and oxygen impurity. Acta Photonica Sin. 2008, 37, 1599-1602.

26. Zhou, J.; DeMiguel-Ramos, M.; Garcia-Gancedo, L.; Iborra, E.; Olivares, J.; Jin, H.; Luo, J.K.; Elhady, A.S.; Dong, S.R.; Wang, D.M.; et al. Characterisation of aluminium nitride films and surface acoustic wave devices for microfluidic applications. Sens. Actuators B Chem. 2014, 202, 984-992. [CrossRef]

27. Zhang, K.; Tao, P.; Zhang, Y.; Liao, X.; Nie, S. Highly thermal conductivity of CNF/ALN hybrid films for thermal management of flexible energy storage devices. Carbohydr Polym 2019, 213, 228-235. [CrossRef]

28. Abe, K.; Iwamoto, S.; Yano, H. Obtaining cellulose nanofibers with a uniform width of $15 \mathrm{~nm}$ from wood. Biomacromolecules 2007, 8, 3276-3278. [CrossRef]

29. Cheng, Q.; Wang, S.; Rials, T.G.; Lee, S.H. Physical and mechanical properties of polyvinyl alcohol and polypropylene composite materials reinforced with fibril aggregates isolated from regenerated cellulose fibers. Cellulose 2007, 14, 593-602. [CrossRef]

30. Cheng, Q.; Wang, S.; Rials, T.G. Poly(vinyl alcohol) nanocomposites reinforced with cellulose fibrils isolated by high intensity ultrasonication. Compos. Part A 2009, 40, 218-224. [CrossRef]

31. Nie, S.; Wang, S.; Qin, C.; Yao, S.; Ebonka, J.F.; Song, X.; Li, K. Removal of hexenuronic acid by xylanase to reduce adsorbable organic halides formation in chlorine dioxide bleaching of bagasse pulp. Bioresour. Technol. 2015, 196, 413-417. [CrossRef]

32. Swain, S.K.; Dash, S.; Behera, C.; Kisku, S.K.; Behera, L. Cellulose nanobiocomposites with reinforcement of boron nitride: Study of thermal, oxygen barrier and chemical resistant properties. Carbohydr. Polym. 2013, 95, 728-732. [CrossRef]

33. French, A.D. Idealized powder diffraction patterns for cellulose polymorphs. Cellulose 2014, 21, 885-896. [CrossRef]

34. Liu, P.; Guo, X.; Nan, F.; Duan, Y.; Zhang, J. Modifying mechanical, optical properties and thermal processability of iridescent cellulose nanocrystal films using ionic liquid. ACS Appl. Mater. Interfaces 2017, 9, 3085-3092. [CrossRef]

35. Jacquet, N.; Quiévy, N.; Vanderghem, C.; Janas, S.; Blecker, C.; Wathelet, B.; Devaux, J.; Paquot, M. Influence of steam explosion on the thermal stability of cellulose fibres. Polym. Degrad. Stab. 2011, 96, 1582-1588. [CrossRef] 
36. Gedler, G.; Antunes, M.; Realinho, V.; Velasco, J.I. Thermal stability of polycarbonate-graphene nanocomposite foams. Polym. Degrad. Stab. 2012, 97, 1297-1304. [CrossRef]

37. Azubuike, C.P.; Rodríguez, H.; Okhamafe, A.O.; Rogers, R.D. Physicochemical properties of maize cob cellulose powders reconstituted from ionic liquid solution. Cellulose 2011, 19, 425-433. [CrossRef]

38. Peng, Y.; Gardner, D.J.; Han, Y.; Kiziltas, A.; Cai, Z.; Tshabalala, M.A. Influence of drying method on the material properties of nanocellulose I: Thermostability and crystallinity. Cellulose 2013, 20, 2379-2392. [CrossRef]

39. Yang, C.T.; Hsiang, H.I.; Huang, T.S.; Huang, P.C.; Han, Y.K. Thermal conductivity and dielectric properties of PEDOT:PSS-ALN filler reinforced water-soluble polymer composites. Ceram. Int. 2017, 43, 710-716. [CrossRef]

(C) 2019 by the authors. Licensee MDPI, Basel, Switzerland. This article is an open access article distributed under the terms and conditions of the Creative Commons Attribution (CC BY) license (http://creativecommons.org/licenses/by/4.0/). 